REGARDS

SUR L'ECONOMIE ALLEMANDE

BULLETIN ECONOMIQUE DUCIRAC

\section{Regards sur l'économie allemande}

Bulletin économique du CIRAC

$95 \mid 2010$

Varia

\title{
Unité allemande
}

ZSCHIESCHE Arnd, ERRICHIELLO Oliver, Erfolgsgeheimnis Ost. SurvivalStrategien der besten Marken - Und was Manager daraus lernen können / CALEFICE Stefan, 20 Jahre Begrüßungsgeld. 100 Mark auf Zeitreise Was ist daraus geworden?

\section{(2) OpenEdition}

\section{Journals}

Édition électronique

URL : http://journals.openedition.org/rea/4067

DOI : $10.4000 /$ rea. 4067

ISBN : 978-2-8218-0886-7

ISSN : 1965-0787

Éditeur

CIRAC

Édition imprimée

Date de publication : 1 mars 2010

ISSN : 1156-8992

Référence électronique

"Unité allemande », Regards sur l'économie allemande [En ligne], 95 | mars 2010, mis en ligne le 08 mars 2010, consulté le 22 septembre 2020. URL : http://journals.openedition.org/rea/4067 ; DOI : https://doi.org/10.4000/rea.4067

Ce document a été généré automatiquement le 22 septembre 2020.

(c) CIRAC 


\section{Unité allemande}

ZSCHIESCHE Arnd, ERRICHIELLO Oliver, Erfolgsgeheimnis Ost. SurvivalStrategien der besten Marken - Und was Manager daraus lernen können / CALEFICE Stefan, 20 Jahre Begrüßungsgeld. 100 Mark auf Zeitreise Was ist daraus geworden?

\section{RÉFÉRENCE}

ZSCHIESCHE Arnd, ERRICHIELLO Oliver, Erfolgsgeheimnis Ost. Survival-Strategien der besten Marken - Und was Manager daraus lernen können, Gabler, Wiesbaden, 2009, $201 \mathrm{p}$.

CALEFICE Stefan, 20 Jahre Begrüßungsgeld. 100 Mark auf Zeitreise - Was ist daraus geworden?, Gabler, Wiesbaden, 2009, 230 p.

1 Pourquoi ne pas considérer l'Unité allemande sous un autre angle? Volonté de réussir, connaissance de leurs forces, adaptation au marché : voici les clés du succès de marques est-allemandes comme le soda Vita Cola ou la pâte à tartiner Nudossi qui, non contentes de prospérer dans les nouveaux Länder, s'imposent désormais à l'ouest. Une recette marketing de portée universelle, censée insuffler du courage aux managers en temps de crise. L'ouvrage de CALEFICE propose quant à lui un voyage temporel depuis la réunification à travers l'économie, la politique et les finances. Ceci en vue de retracer la destinée hypothétique des 100 Marks de bienvenue (Begrüßungsgeld) alloués aux 16,4 millions de citoyens de la RDA à la fin de l'année 1989. (sh) 